\title{
Effect of Gear Oil on the Surface of a Transmission Gearbox
}

\author{
Tarun Gupta ${ }^{1}$, Vikas Chauhan ${ }^{2}$, Rajat Jain ${ }^{3}$, Pravin P Patil ${ }^{4}$ \\ ${ }^{1,2}$ Department of Thermal Engineering, Faculty of Technology, UTU Dehradun, India. \\ ${ }^{3,4}$ Department of Thermal Engineering, Graphic Era University, Dehradun, India.
}

\begin{abstract}
Transmission Gearbox plays a vital role and essential part of an automobile. It provide torque and transmit power from one section to another. The torque is inversely related to speed i.e. lower speed have higher torque and vice versa. The main motive of this research work is to measure the surface temperature variation on the gearbox surface with the help of probe method. In this dissertation work, steady state thermal analysis of a gear train was performed by using Ansys 16.2 and apply probe method to get the temperature at a particular point on a gear surface. The analysis can be done to prevent the gearbox from failure. There are variant reason for the failure of transmission gearbox is meshing excitation, load fluctuation, thermal stress etc. For performing probe method with the help of steady state thermal analysis, two material i.e. SAE 8620 and AISI 9310 are consider foe manufacturing helical gear and rotating shaft. SAE 80W-90 gear oil were used as a lubricant in a transmission gearbox. In steady state thermal state, two boundary condition were applied i.e. gear oil temperature $70^{\circ} \mathrm{C}$ and $75^{\circ} \mathrm{C}$ and varying convective heat transfer coefficient(h) $100 \mathrm{~W} / \mathrm{m}^{2}{ }^{\circ} \mathrm{K}$ to 600 $\mathrm{W} / \mathrm{m}^{2}{ }^{\circ} \mathrm{K}$. In this analysis, the dynamic loading effect and gear oil heating on the surface were considered. The simulation results were found in the form of colour code having temperature profile with maximum temperature at $70^{\circ} \mathrm{C}$ is $69.60^{\circ} \mathrm{C}$ and $75^{\circ} \mathrm{C}$ is $74.55^{\circ} \mathrm{C}$. As steady state thermal analysis was completed, apply probe method to find out the variation on gearbox surface. The Solid Edge and Pro-E are the designing software which are used in designing the transmission gearbox.
\end{abstract}

\section{Introduction}

Gear oil is a lubricant prepare mainly for transmission, transfer case in automobile. It is of high viscosity for better protection of gear and generally associated with a strong sulphur smell. The high viscosity certifies transferal of lubricant throughout the gear train. The transmission gearbox is one of the crucial device which provide speed, power and torque. The device is attached between the engine and driving wheel. The energy from the engine would help to engender power or torque as per the necessity and transfer to the wheel. In transmission gearbox assembly, gear oil is used as a lubricant for cooling gear train and released the heat to cooling fluid of radiator. Gear oil provide friction durability, good sealing, non-corrosive and antifoam to gear train parts and mean component of gearbox casing.

Many researchers have studied on various component of a transmission gearbox i.e. casing, gear oil properties, gear train assembly, role of gear oil on gear train assembly. Ashwani Kumar et al. [1] have studied the effect of mechanical properties of material on natural frequency and mode shape of heavy vehicles gearbox. They analyse four material i.e. grey cast iron, $\mathrm{Mg}$ and $\mathrm{Al}$ alloy and structural steel on the design and vibration index based. The vibration response for all material shows the natural frequency vibration of $1002 \mathrm{~Hz}$ to 3879 $\mathrm{Hz}$ and different vibration modes shapes. Marina Franulovic et al. [2] have studied gear fatigue failure occurrence due to assembly error by load fluctuation, gear design error. Salah et al. [3] have deliberate radiator heat exchanger which is used for transmission oil cooling. The objective of this study is to predict the relation between transmission cooling and vehicles fuel economy.

V. S Khangar et al. [4] have deliberate various method to analyse the cause of the failure of shaft. Different methodologies was studied to examine the shaft failure of bridle roll shaft used continuously in steel industry. After analysis the cause of failure of shaft was fatigue load. K. Mao et al. [5] had investigated on acetal gear and make concentration on acetal gear wear behaviour and its behaviour based on the gear thermal and mechanical contact. They found acetal gear wear rate was increased intensely when load reaches the critical value for the particular geometry and operating condition. These gear was loaded below the critical value. The main reason for the increment in wear rate is the gear operating temperature reaches the material melting point under critical load condition. The gear have some advantages related to metal gear i.e. low cost and weight, high efficiency, quietness of operation and functioning without external lubrication.

\section{Modellingand Boundary Condition of Transmission Gearbox}

The transmission gearbox have very complex and critical geometry and required lot of time and patience. The creation of geometry require reliable and relevant software. Solid Edge and Pro-E are used for the formation of transmission gearbox. Around more than 600 component are creating including counter shaft, main 
shaft, input shaft, bearing, bearing braces, helical gear and synchroniser. The simulation and FEA had done on ANSYS 16.2 software. Finite element analysis are used for the calculation of various results and help for estimating the product performance. It is generally acceptable process of retrievingproduct enactment without the necessity of physical building and testing.

In this simulation, we have consider two material i.e. SAE 8620 are used for helical gear and AISI 9310 are used for rotating shaft manufacturing. SAE $80 \mathrm{~W}-90$ is the gear oil which is used as a lubricant. Figure 1 shows the full assembly of transmission gearbox and figure 2 shows the meshed model of gearbox. This model have $3,42,275$ nodes and $1,88,431$ elements.

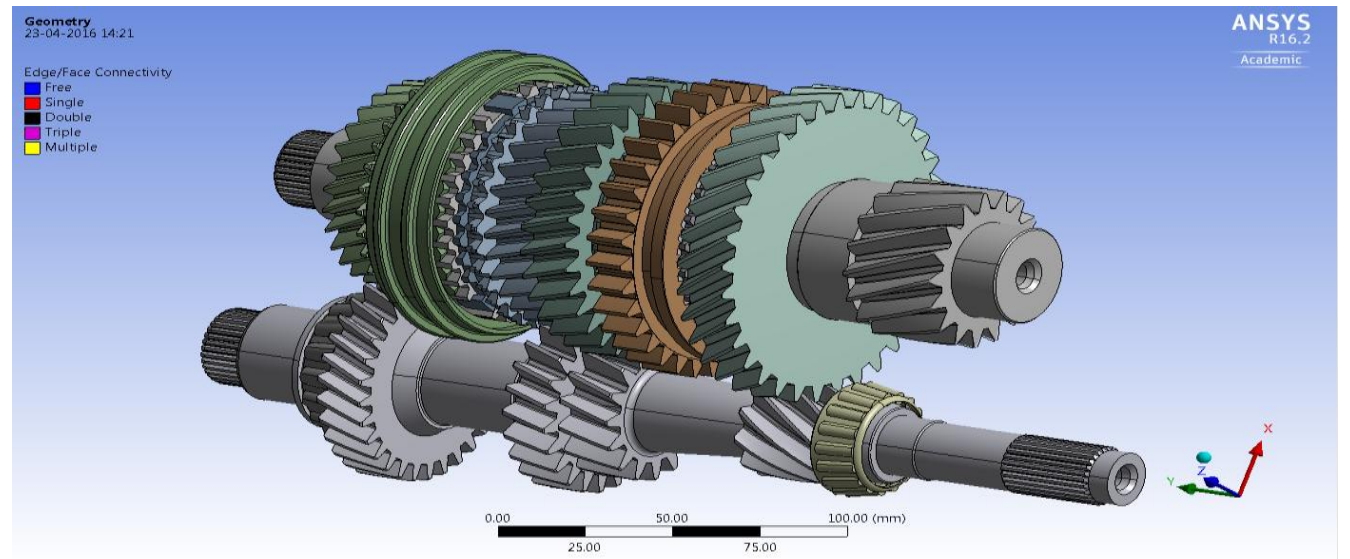

Figure 1: CadModel of Transmission Gearbox

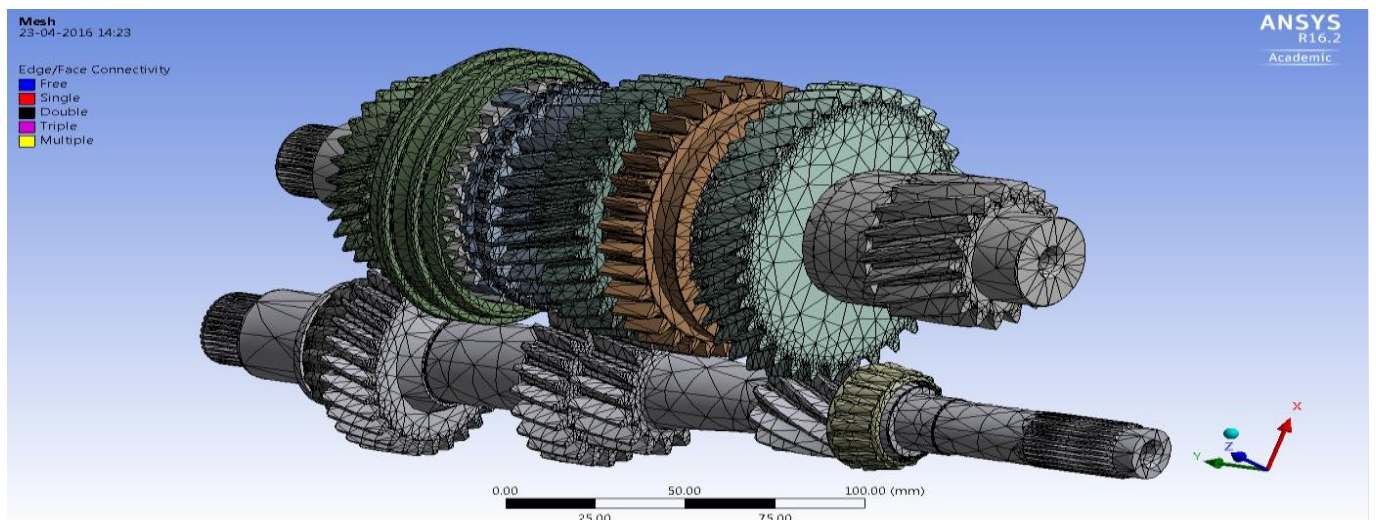

Figure2: Meshed Model of Transmission Gearbox

The arithmetical simulation was performed for the thermal analysis of gear train under the effect of load, rotational speed and convective heat transfer coefficient. Gear oil plays a role of lubricant to cool the gears and transferral the heat through convective process. As we know the overheating of gears diminishes the efficiency and life span of gears. The replacement of gear or gearbox assembly is very costly. The objective of this study is to increase the life span of gear train. The aim is fulfil by applying required and accurate boundary condition and main boundary condition for the thermal analysis of gearbox is gear oil temperature $70^{\circ} \mathrm{C}$ and $75^{\circ} \mathrm{C}$ and varying convective heat transfer coefficient is $100 \mathrm{~W} / \mathrm{m}^{2}{ }^{\circ} \mathrm{K}$ to $600 \mathrm{~W} / \mathrm{m}^{2}{ }^{\circ} \mathrm{K}$. As we simulate the whole geometry, we found that maximum thermal stress area is found on the right hand side of the counter shaft in red colour. The thermal stress of gearbox are shown in the form of colour codes. As we found the stress concentrating area then we apply probe method to check the variation of stress in a particular region on a different gears.

\section{Probe Method on Steady State Thermal Analysisat Gearoil Temperature $7^{\circ} \mathrm{C}$ and Convective Heat Transfer Coefficient $100 \mathrm{~W} / \mathrm{M}^{2}{ }^{\circ} \mathrm{K}$ To $600 \mathrm{~W} / \mathrm{M}^{2}{ }^{\circ} \mathrm{K}$.}

Probe is a method in which we found a value of a temperature at a required point on the surface of a gear. The value of temperature on the surface of gear using gear oil temperature $70^{\circ} \mathrm{C}$ and varying convective heat transfer coefficient of $100 \mathrm{w} / \mathrm{m}^{2}{ }^{\circ} \mathrm{k}$ to $600 \mathrm{w} / \mathrm{m}^{2}{ }^{\circ} \mathrm{k}$ are shown in figure- 


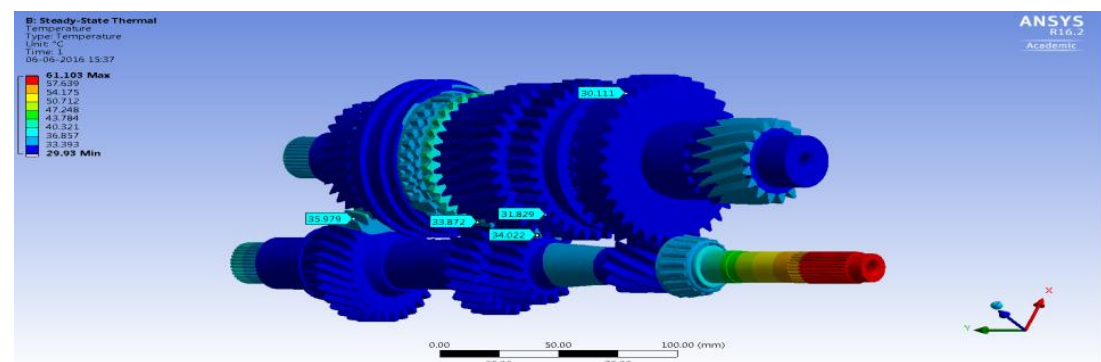

Figure 3: Probe temperature value when gear oil temperature $70^{\circ} \mathrm{C}$ and convective heat transfer coefficient is $100 \mathrm{w} / \mathrm{m}^{2}{ }^{\circ} \mathrm{k}$.

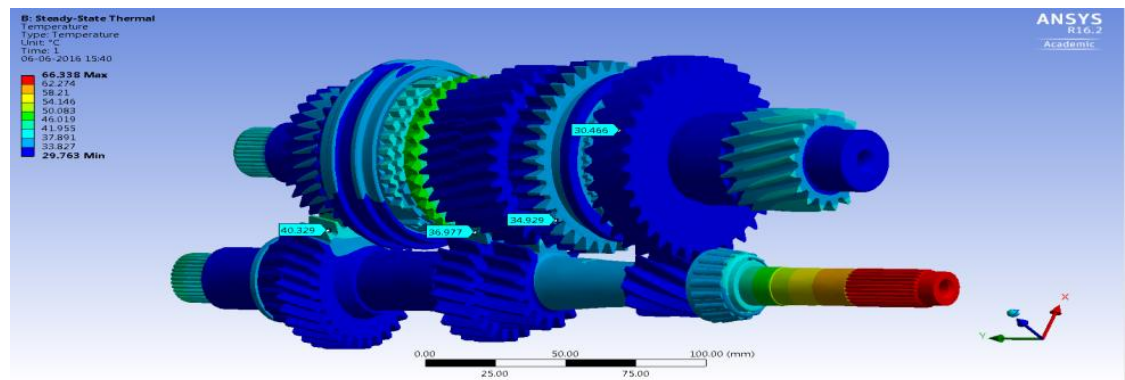

Figure 4: Probe temperature value when gear oil temperature $70^{\circ} \mathrm{C}$ and convective heat transfer coefficient is $200 \mathrm{w} / \mathrm{m}^{2}{ }^{\circ} \mathrm{k}$.

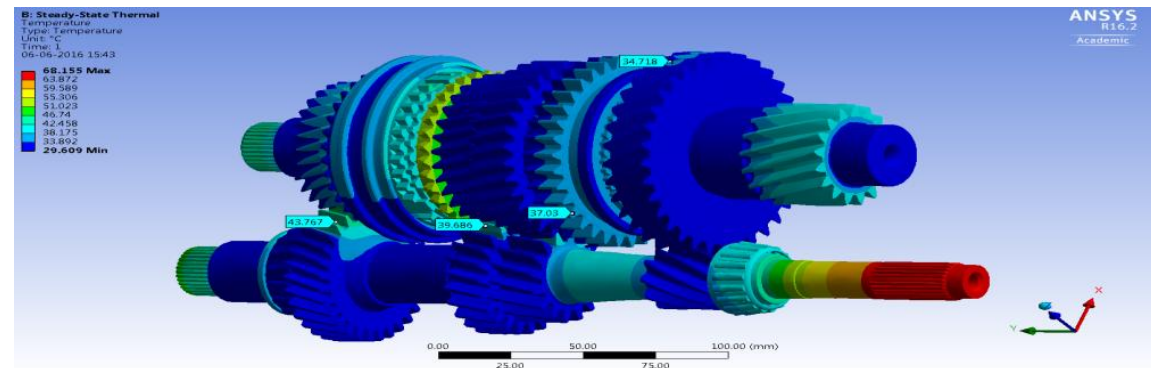

Figure 5: Probe temperature value when gear oil temperature of $70^{\circ} \mathrm{C}$ and convective heat transfer coefficient $300 \mathrm{w} / \mathrm{m}^{2}{ }^{\circ} \mathrm{k}$.

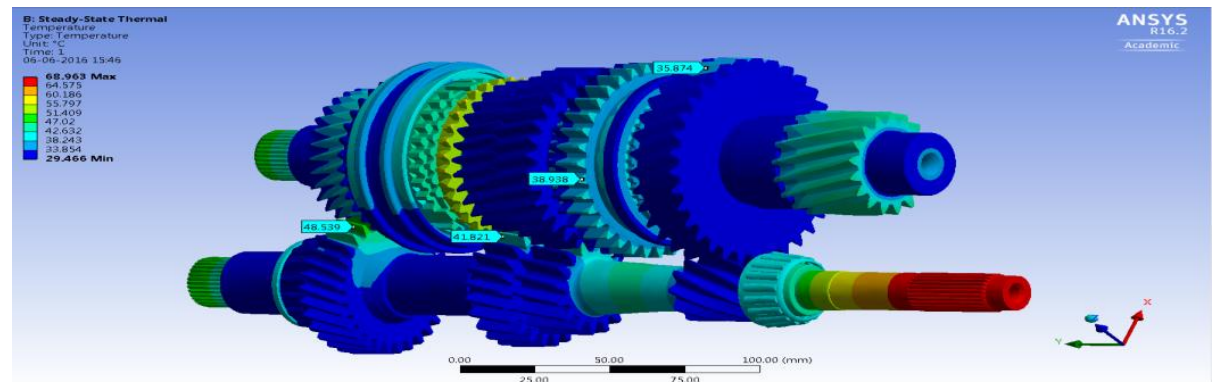

Figure 6: Probe temperature value when gear oil temperature $70^{\circ} \mathrm{C}$ and convective heat transfer coefficient $400 \mathrm{w} / \mathrm{m}^{2}{ }^{\circ} \mathrm{k}$.

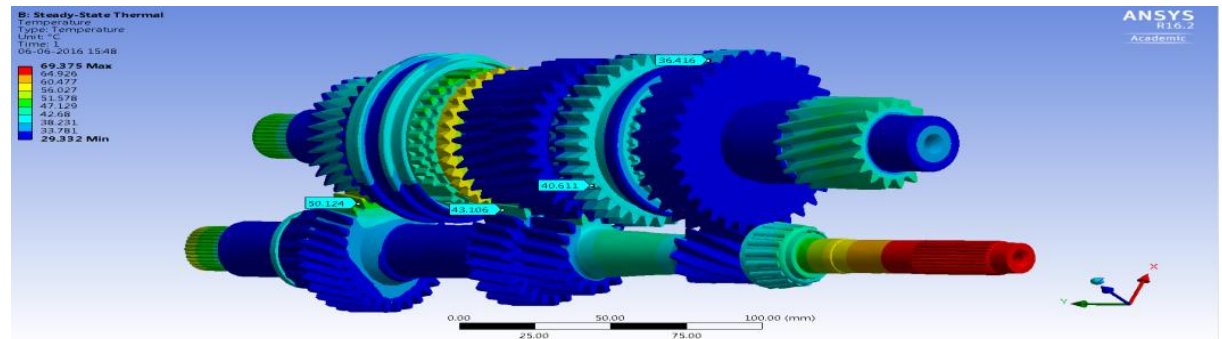

Figure 7: Probe temperature value when gear oil temperature $70^{\circ} \mathrm{C}$ and convective heat transfer coefficient $500 \mathrm{w} / \mathrm{m}^{2}{ }^{\circ} \mathrm{k}$. 


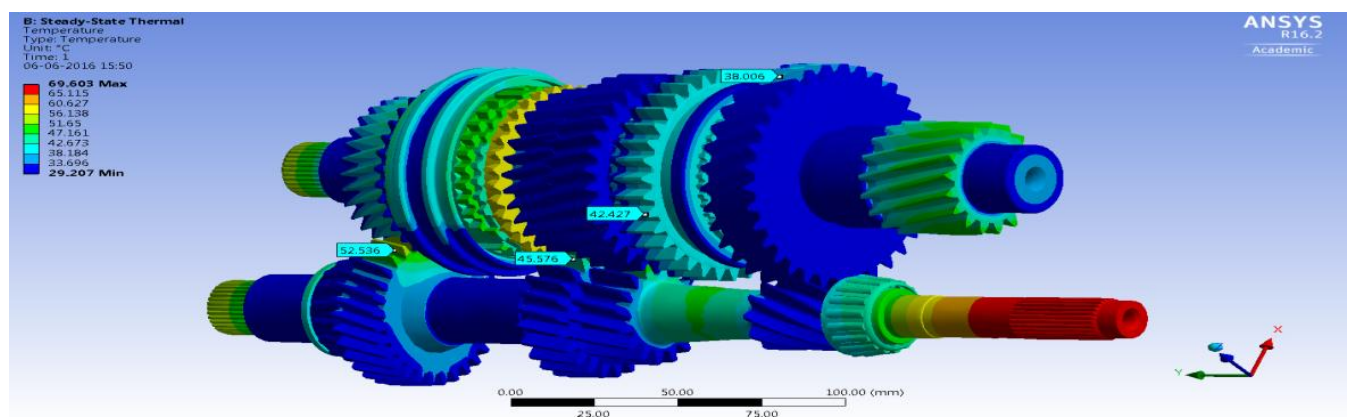

Figure 8: Probe temperature value when gear oil temperature $70^{\circ} \mathrm{C}$ and convective heat transfer coefficient $600 \mathrm{w} / \mathrm{m}^{2}{ }^{\circ} \mathrm{k}$.

\section{Probe Methodon Steady State Thermal Analysisat Gear Oil Temperature $75^{\circ} \mathrm{C}$ And Convective Heat Transfer Coefficient $100 \mathrm{~W} / \mathrm{M}^{2}{ }^{\circ} \mathrm{K}$ To $600 \mathrm{~W} / \mathrm{M}^{2}{ }^{\circ} \mathrm{K}$.}

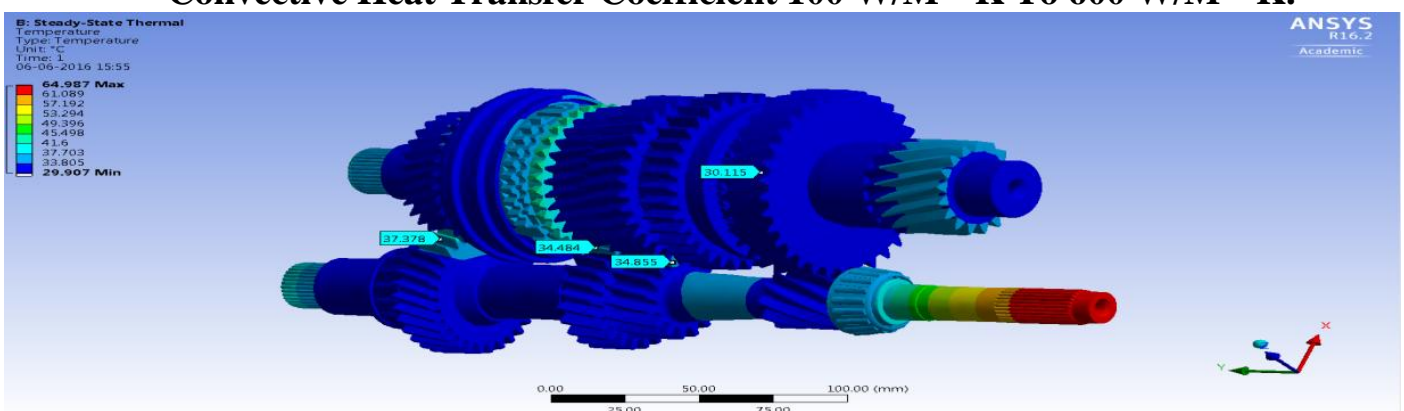

Figure 9: Probe temperature value when gear oil temperature $75^{\circ} \mathrm{C}$ and convective heat transfer coefficient $100 \mathrm{w} / \mathrm{m}^{2}{ }^{\circ} \mathrm{k}$

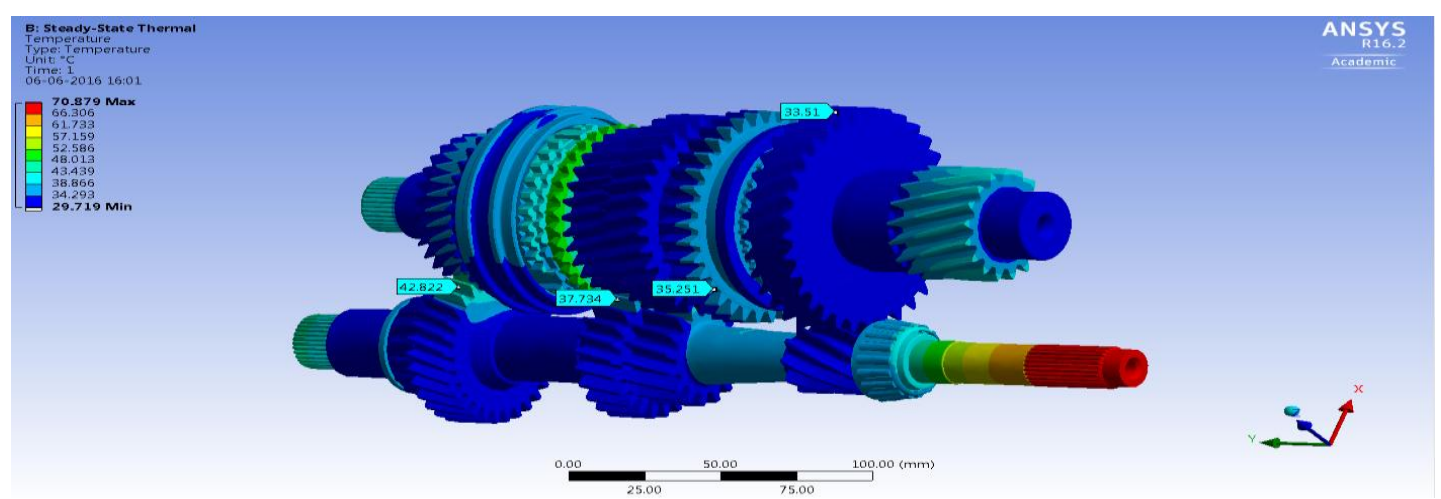

Figure 10: Probe temperature value when gear oil temperature $75^{\circ} \mathrm{C}$ and convective heat transfer coefficient $200 \mathrm{w} / \mathrm{m}^{2}{ }^{\circ} \mathrm{k}$

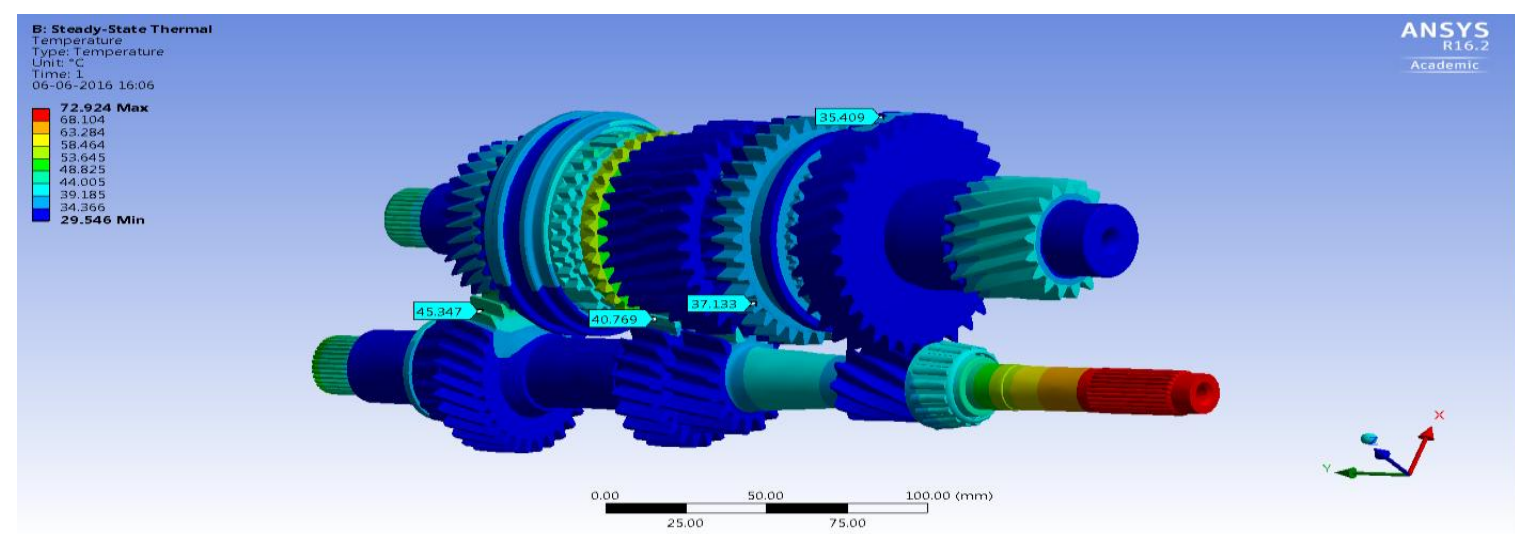

Figure 11: Probe temperature value when gear oil temperature $75^{\circ} \mathrm{C}$ and convective heat transfer coefficient $300 \mathrm{w} / \mathrm{m}^{2}{ }^{\circ} \mathrm{k}$ 


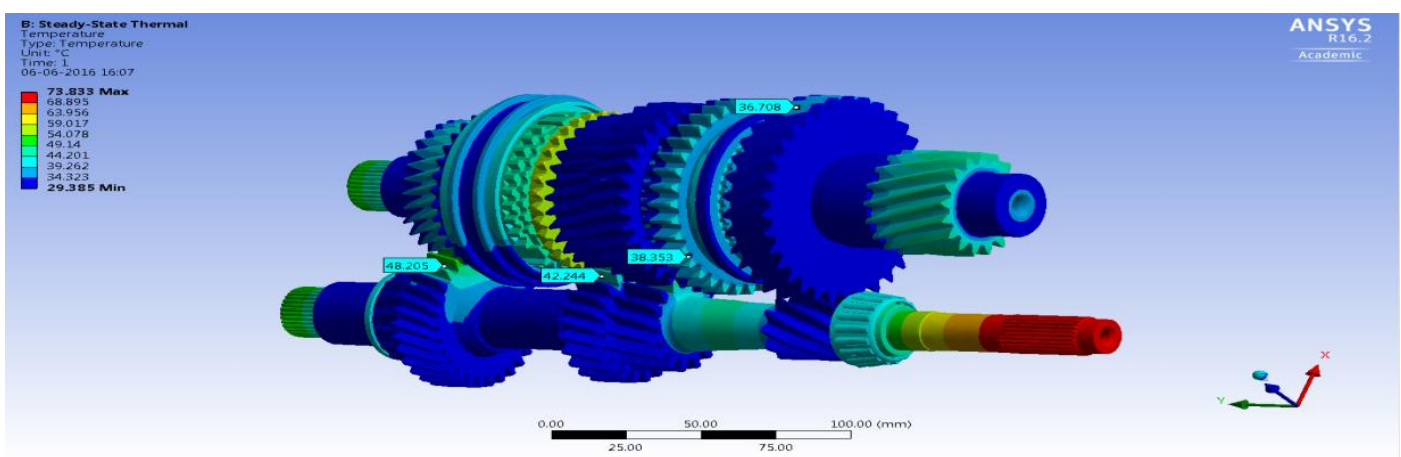

Figure 12: Probe temperature value when gear oil temperature $75^{\circ} \mathrm{C}$ and convective heat transfer coefficient $400 \mathrm{w} / \mathrm{m}^{2}{ }^{\circ} \mathrm{k}$

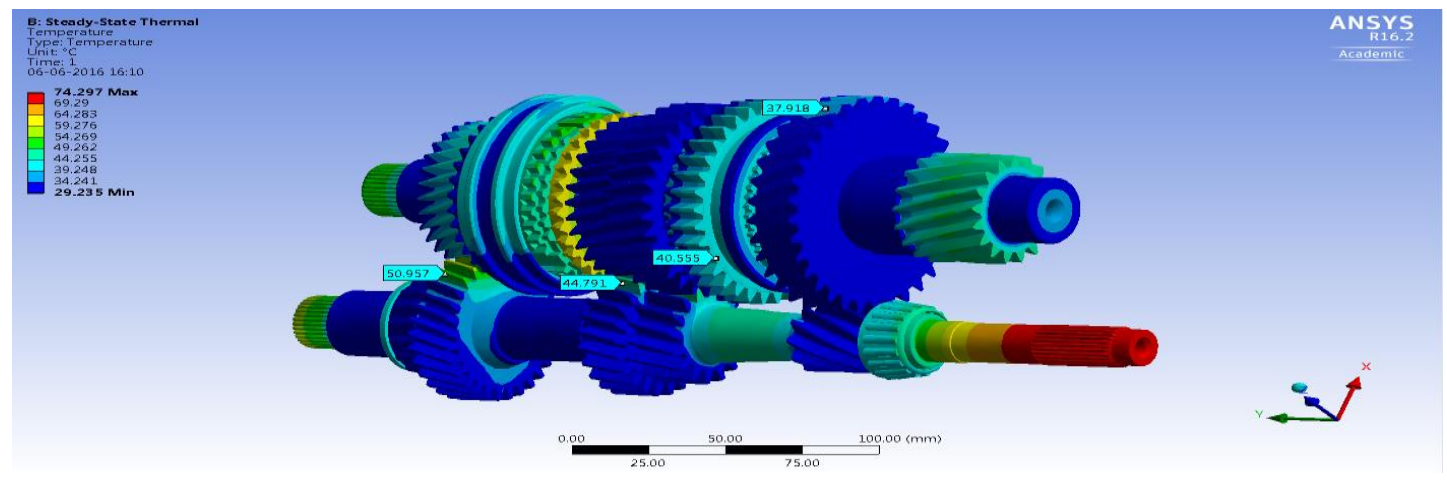

Figure 13: Probe temperature value when gear oil temperature $75^{\circ} \mathrm{C}$ and convective heat transfer coefficient $500 \mathrm{w} / \mathrm{m}^{2}{ }^{\circ} \mathrm{k}$

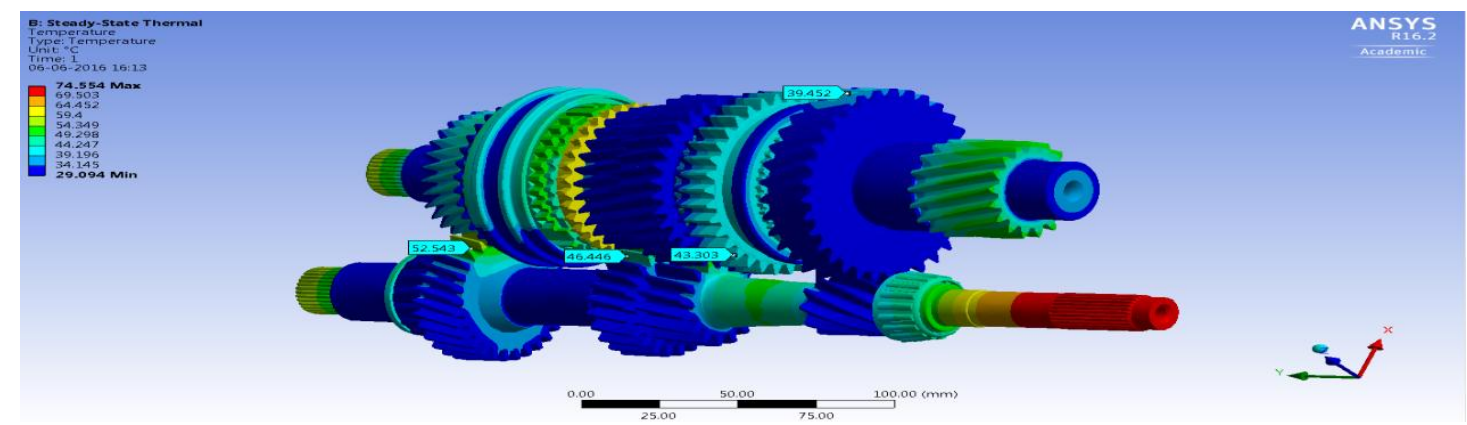

Figure 14: Probe temperature value when gear oil temperature $75^{\circ} \mathrm{C}$ and convective heat transfer coefficient $600 \mathrm{w} / \mathrm{m}^{2}{ }^{\circ} \mathrm{k}$

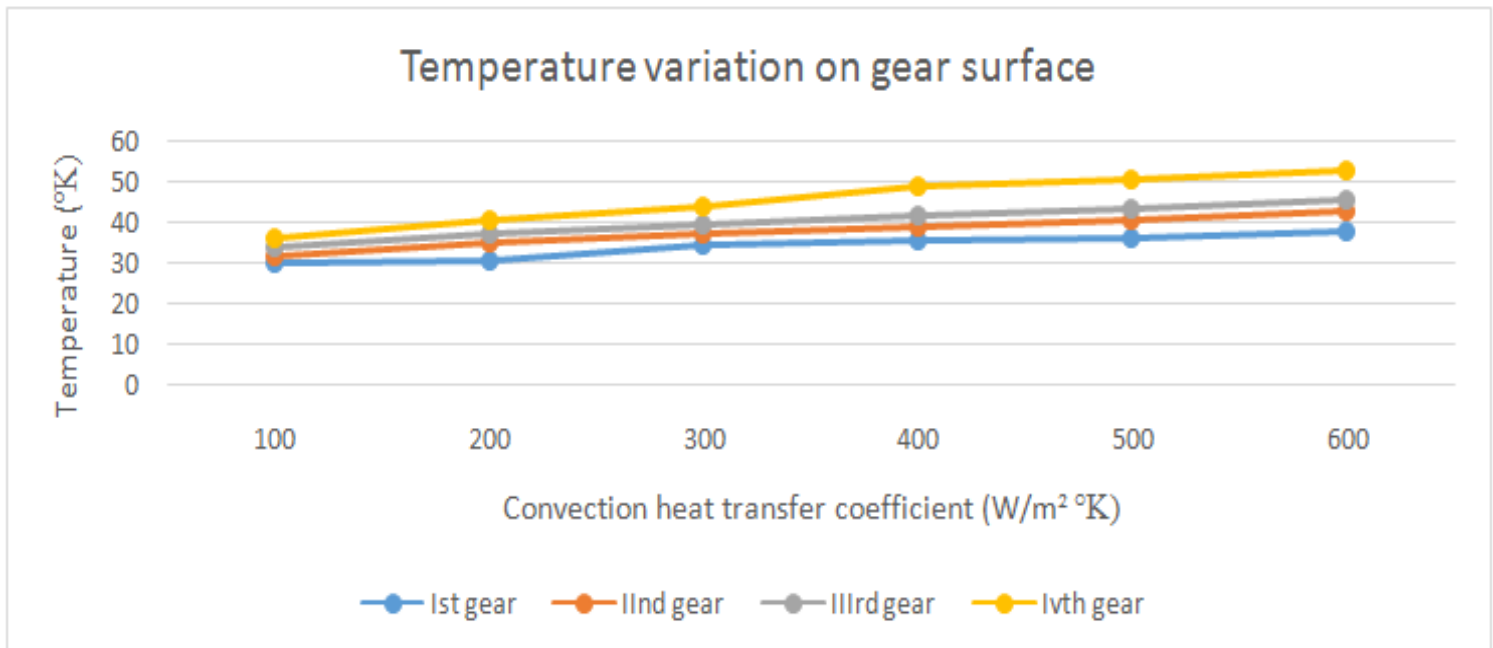

Figure 15: Temperature Variation on Each Gear Surface at $70^{\circ} \mathrm{C}$ and $100-600 \mathrm{~W} / \mathrm{m}^{2}{ }^{\circ} \mathrm{K}$ 


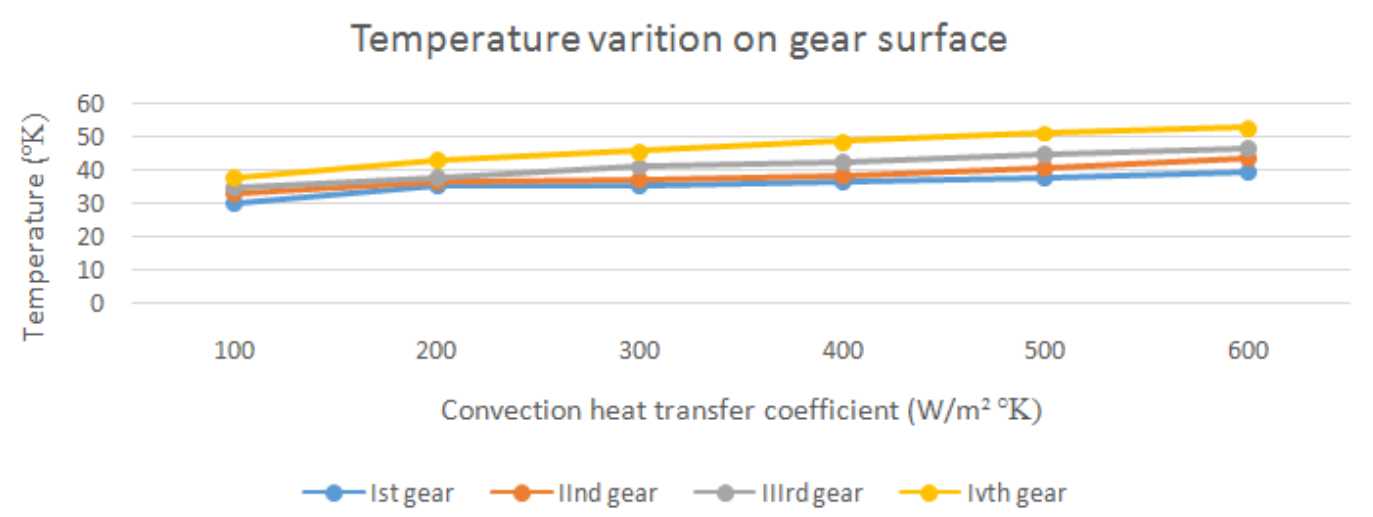

Figure 16: Temperature Variation on Each Gear Surface at $75^{\circ} \mathrm{C}$ and $100-600 \mathrm{~W} / \mathrm{m}^{2}{ }^{\circ} \mathrm{K}$

After implement the boundary condition i.e. Gear oil temperature at $70^{\circ} \mathrm{C}$ and $75^{\circ} \mathrm{C}$ and varying convective heat transfer coefficient $100 \mathrm{~W} / \mathrm{m}^{2}{ }^{\circ} \mathrm{K}$ to $600 \mathrm{~W} / \mathrm{m}^{2}{ }^{\circ} \mathrm{K}$, we found that stress concentrating area is at right hand side of counter shaft in red colour and minimum stress area is on the surface of a gear. Some stress concentrating area are on the surface of gear and value of these stress are found with the help of probe method. The maximum value of temperature at $70^{\circ} \mathrm{C}$ is $69.60^{\circ} \mathrm{C}$ and $75^{\circ} \mathrm{C}$ is $74.55^{\circ} \mathrm{C}$. Figure 15 and 16 shows the temperature variation on the surface of gearbox under dynamic loading. After plotting the probe value at $70^{\circ} \mathrm{C}$ and $75^{\circ} \mathrm{C}$, we found that the variation of temperature on the surface of gear varies gradually and the difference in maximum temperature is $4.95^{\circ} \mathrm{C}$.

\section{Conclusion}

Steady state thermal analysis are carried out on multi speed transmission gearbox with the help of gear oil temperature $70^{\circ} \mathrm{C}$ and $75^{\circ} \mathrm{C}$ and varying convective heat transfer coefficient $100 \mathrm{~W} / \mathrm{m}^{2}{ }^{\circ} \mathrm{K}$ to $600 \mathrm{~W} / \mathrm{m}^{2}{ }^{\circ} \mathrm{K}$. This analysis is performed to know the effect of thermal analysis on the surface of gearbox having different materials. The transmission gearbox and gear oil have a non-linear problem. After FEA analysis, the gear train temperature surface profile varies progressively and linearly. These material i.e. SAE 8620 and AISI 9310 have designing significance and probe method signify that the stress variation on the surface of a gearbox is minor and does not effect on the designing stage of transmission gearbox. In future this research work can be extended by using different materials and different loading conditions.

\section{Acknowledgement}

Author would like to thank Department of Science and Technology (DST) Government of India for necessary funding of Advanced Modelling and Simulation Lab to carry out this research work.

\section{References}

[1] Ashwani Kumar, Himanshu Jaiswal, Rajat Jain, Pravin P Patil (2014), Free Vibration and Material Mechanical Properties Influence Based Frequency and Mode Shape Analysis of Transmission Gearbox Casing, Procedia Engineering, Vol 97, PP 1097-1106.

[2] Marina Franulovic, Robert Basan, Robert Kunc Ivan Prebil (2011), Numerical Modelling of Life Prediction of Gear, Procedia Engineering, Vol. 10, PP 562-567.

[3] Salah, M. H., Mitchell, T. H., Wagner, J. R., \& Dawson, D. M. (2007, June). Multiple Cooling Loops in Advanced Vehicle Thermal Management Systems. IEEE/ASME Transactions on Mechatronics.

[4] Solid Edge .Version 19.0.2006.

[5] V.S. Khangar, Dr. S.B Jaju (2012), A Review of Various Methodologies used for Shaft Failure Analysis, IJETAE, Vol 2, Issue 6, PP 50-54.

[6] Pro-E 5.0. Designing guide manual, 2013.

[7] ANSYS R 14.5, Academic, Structural analysis guide (2013).

[8] K. Mao, W.Li, C.J.Hooke, D.Walton (2010), Polymer Gear Surface Thermal Wear and its Performance Prediction, Tribology International, Vol 43, PP 433-439. 